\title{
Activation of the Plasma Clotting, Fibrinolytic, and Kinin-Kallikrein System in Preterm Infants with Severe Idiopathic Respiratory Distress Syndrome
}

\author{
FRANK BRUS, WILLEM VAN OEVEREN, ALBERT OKKEN, \\ AND SIDARTO BAMBANG OETOMO \\ Beatrix Childrens Hospital, Division of Neonatology [F.B., A.O., S.B.O.], and Department of \\ Cardio-Pulmonary Surgery, Blood Compatibility Research Center [W.v.O.], University Hospital \\ Groningen, The Netherlands
}

\section{ABSTRACT}

We studied the activation pattern of clotting, fibrinolysis, and kinin-kallikrein during the first $5 \mathrm{~d}$ of life in 10 preterm infants with signs of severe idiopathic respiratory distress syndrome (IRDS) after birth (IRDS group) and in 12 healthy preterm infants (reference group). We found systemic activation of clotting, fibrinolysis, and kininkallikrein in the IRDS infants within 12 to $24 \mathrm{~h}$ of birth, represented by increased median thrombin-antithrombin III complex formation $(90 \mathrm{ng} / \mathrm{mL}$ versus $10 \mathrm{ng} / \mathrm{mL}$ in the reference group, $p<0.05$ ), increased mean tissue-type plasminogen activator plasma concentrations $(11.8 \mathrm{ng} / \mathrm{mL}$ versus $3.5 \mathrm{ng} / \mathrm{mL}$ in the reference group, $p<0.05)$, and increased mean plasma kallikrein activity $(182.6 \%$ versus $162.0 \%$ of maximal activated human plasma in the reference group, $p<0.05$ ), respectively. Clotting activation was accompanied by a significant decrease of the platelet count. Clotting and fibrinolytic activity decreased in the IRDS group during the first 2 to $3 \mathrm{~d}$ of life. Kinin-kallikrein activation was accompanied by decreased plasma kallikrein inhibitor activity values and did not change through- out the study period. Plasma factor XII activity was not significantly increased in the IRDS infants during the first 2 $\mathrm{d}$ of life but did significantly increase thereafter. The cause of simultaneous activation of clotting, fibrinolysis, and kinin-kallikrein in our IRDS infants has not yet been clarified. However, this activation process may contribute to lung injury such as that described in the adult respiratory distress syndrome.(Pediatr Res 36: 647-653, 1994)

Abbreviations
IRDS, idiopathic respiratory distress syndrome
CPP, cryoglobulin poor plasma
AT III, antithrombin III
T-AT III, thrombin-antithrombin III
F XIIa, factor XII activity
t-PA, tissue-type plasminogen activator
PKKI, plasma kallikrein inhibitor activity
\% AHP, percentage of maximal activated human plasma
\% NHP, percentage of normal human plasma

Intraalveolar and intravascular deposition of fibrin has been found in preterm infants suffering from IRDS $(1,2)$. These fibrin depositions are likely to contribute to respiratory insufficiency. Intraalveolar fibrin, a major component of hyaline membranes, inactivates considerable amounts of surfactant (1-3). Intravascular fibrin, found at autopsy in the lungs of preterm infants who died of severe IRDS, decreases surfactant synthesis due to impaired lung perfusion $(1,2)$. These intraalveolar and intravascular fibrin depositions are the result of activation of the clotting system represented

Received December 23, 1993; accepted May 17, 1994.

Correspondence: Frank Brus, M.D., Beatrix Childrens Hospital, Division of Neonatology, University Hospital Groningen, Oostersingel 59, 9713 EZ Groningen, The Netherlands. by thrombin formation and AT III consumption, as has been reported in preterm infants with severe neonatal IRDS (4).

Simultaneous systemic activation of the clotting, fibrinolytic, and kinin-kallikrein system has been described in several severe clinical disorders in adults and children that lead to the adult respiratory distress syndrome (5-7). Activation of these plasma protein systems is considered responsible for impaired hemostasis and subsequent formation of microthrombi, thus causing decreased perfusion of organs $(8,9)$. Furthermore, activation of the kinin-kallikrein system causes increased vascular permeability with edema formation (10). It has been shown that the lungs are primarily affected by this systemic activation process $(5,6)$. 
We hypothesized that similar simultaneous activation of plasma protein systems occurs in the first days of life in preterm infants with respiratory insufficiency due to IRDS. Therefore, we studied the activation pattern of different components of the clotting, fibrinolytic, and kinin system during the first $5 \mathrm{~d}$ of life in preterm infants with respiratory failure from birth and with clinical and radiologic signs of IRDS.

\section{METHODS}

Patients. The study included 22 preterm infants who were consecutively admitted to the neonatal intensive care unit of the Beatrix Childrens Hospital, University Hospital of Groningen, between October 1, 1992 and January 1, 1993. These infants were born in the Department of Obstetrics of the University Hospital of Groningen and met the following criteria for enrollment: 1 ) gestational age between 28 and $33 \mathrm{wk} ; 2$ ) birth weight appropriate for gestational age; and 3) no major congenital malformations or evidence of infection. Ten infants showed clinical and radiologic signs of severe IRDS, ventilatory dependency, and oxygen requirement of more than $30 \%$ for adequate oxygenation (IRDS group). Twelve healthy preterm infants served as a reference group. The study was approved by the medical ethical committee of the University Hospital of Groningen. Informed consent was given by the parents.

The infants of the IRDS group and the reference group were not different for prenatal factors that may influence the activation pattern of the clotting, fibrinolytic, and kinin-kallikrein systems (Table 1). Dexamethasone was given to the mothers of three infants in both the IRDS and the reference group before delivery. Dexamethasone is known to have inhibitory effects on the fibrinolytic system (11). However, activation of fibrinolysis in the three IRDS infants whose mothers received dexamethasone could not be distinguished from that in the other IRDS infants, whereas it was practically absent in the three reference infants. No other specific drugs that could influence the activation

Table 1. Prenatal factors that may influence the activation pattern of the studied plasma protein systems: comparison between IRDS and reference infants*

\begin{tabular}{lcc}
\hline & $\begin{array}{c}\text { IRDS } \\
(n=10)\end{array}$ & $\begin{array}{c}\text { Reference } \\
(n=12)\end{array}$ \\
\hline Premature labor & $6(60)$ & $6(50)$ \\
PROM & $2(20)$ & 0 \\
HELLP mother & $3(30)$ & $4(30)$ \\
Route of delivery & & \\
$\quad$ SVD & $4(40)$ & $6(50)$ \\
CS & $6(60)$ & $6(50)$ \\
Dexamethasone given to mother & $3(30)$ & $3(25)$ \\
\hline
\end{tabular}

* Data are presented as number with percentage in parentheses. PROM, premature rupture of membranes; HELLP, the syndrome of hemolysis, elevated liver enzymes, and low platelet count; SVD, spontaneous vaginal delivery; CS, caesarean section. There were no significant differences between the IRDS and the reference group with regard to the prenatal factors. process investigated in this study, such as anticoagulants or indomethacin, were given to the mothers.

Postnatal characteristics of both the IRDS and the reference group are presented in Table 2. All IRDS infants had birth asphyxia and showed clinical signs of respiratory insufficiency requiring endotracheal intubation and artificial ventilation from birth. Despite low Apgar scores and low arterial umbilical $\mathrm{pH}$ values at birth, no organ failure other than respiratory insufficiency existed in these infants.

Patient management. All IRDS infants were artificially ventilated throughout the study period to maintain the arterial $\mathrm{PO}_{2}$ between 7.5 and $10.0 \mathrm{kPa}$ and the arterial $\mathrm{PCO}_{2}$ between 5.5 and $6.5 \mathrm{kPa}$. When infants showed clinical signs of respiratory distress, required more than $30 \%$ oxygen for adequate oxygenation, and needed artificial ventilation because of respiratory insufficiency, they were eligible for the Dutch Multicenter study "Nedsurf" for surfactant replacement therapy (Alvofact, Boehringer, Ingelheim, Germany). In the Nedsurf study, IRDS infants are prospectively classified according to the roentgenologic severity of the disease using the Giedion score (12). Infants showing Giedion 1 or 2 abnormalities on a chest $\mathrm{x}$-ray were considered to have moderate IRDS, whereas infants with a Giedion 3 or 4 chest $x$-ray were considered to have severe IRDS. In our study, all infants of the IRDS group had severe IRDS. According to the criteria of the Nedsurf study, eight of the 10 infants of the IRDS group received surfactant $(100 \mathrm{mg} / \mathrm{kg}$ body weight endotracheally). The remaining two infants were not given surfactant because of severe circulatory insufficiency.

Infants of less than 34 wk gestational age with respiratory failure requiring artificial ventilation or continuous positive airway pressure were examined with echocardiography for patency of the ductus arteriosus on the second to fourth day of life. A patent ductus arteriosus was treated with one or two courses ( 3 times $0.2 \mathrm{mg} / \mathrm{kg}$ ) of i.v. indomethacin (Indocid, Merck Sharpe \& Dohme, Haarlem, The Netherlands). In our study, six IRDS infants were treated with indomethacin.

Infants received standard supportive care and transfusions of CPP or packed red blood cells combined with

Table 2. Postnatal characteristics of IRDS and reference infants*

\begin{tabular}{lcc}
\hline & $\begin{array}{c}\text { IRDS } \\
(n=10)\end{array}$ & $\begin{array}{c}\text { Reference } \\
(n=12)\end{array}$ \\
\hline Gestational age, (wk) & $29.1 \pm 1.0$ & $30.7 \pm 1.7$ \\
Birth weight $(\mathrm{g})$ & $1126 \pm 156$ & $1404 \pm 321$ \\
Apgar score & & \\
1 min & 3 (range 1-6) & 7 (range 5-9) $\dagger$ \\
5 min & 6 (range 2-9) & 9 (range 7-10) $\dagger$ \\
Sex & $3(33)$ & $7(70)$ \\
Female & $6(67)$ & $3(30)$ \\
Male & $7.18 \pm 0.07$ & $7.26 \pm 0.04 \dagger$ \\
Arterial umbilical pH &
\end{tabular}

* Data presented as mean \pm SD or as number with percentage in parentheses.

$\dagger p<0.01$. 
CPP to replace blood that was taken for laboratory tests. The IRDS infants received a mean of three (range one to five) transfusions with packed red blood cells and CPP and a mean of one (range zero to three) transfusion with $\mathrm{CPP}$ per infant during the first $5 \mathrm{~d}$ of life. These transfusions did not exceed $10 \%$ of the calculated blood volume in any 24-h period, except for one IRDS infant who received a total of eight transfusions (four transfusions of CPP with packed red blood cells and four transfusions of CPP without packed red blood cells) during the whole study period. CPP is stored frozen and contains native inactive plasma proteins, whereas packed red blood cells contain only $10-20 \%$ plasma, including plasma proteins, which are slightly activated by the processing procedure (13). Therefore, we do not consider these transfusions to influence the results of our study, even in the infant who received a total of eight transfusions.

A venous or arterial umbilical catheter was only inserted after approval of the attending neonatologist. The patency of arterial umbilical catheters was maintained by a continuous infusion of $0.9 \% \mathrm{NaCl}$ solution containing 3 $\mathrm{U} / \mathrm{mL}$ heparin at a rate of $0.5-0.7 \mathrm{~mL} / \mathrm{h}$. It has been demonstrated that this low-dose heparin infusion does not influence clotting in preterm infants (14). All infants of the IRDS group had a venous umbilical catheter, and six of them also had an arterial umbilical catheter. None of the infants in the reference group received an umbilical catheter.

Study protocol. Blood samples were taken from the venous umbilical catheter (IRDS infants) or were obtained by direct venipuncture (reference infants). For ethical reasons, we were not allowed to insert a venous umbilical catheter into the preterm infants of the reference group who were otherwise healthy and therefore did not require any type of central line. We were aware of the susceptibility of some parameters to sampling errors. We tried to minimize the influence of the different sampling techniques on these parameters. Venous umbilical catheters in the IRDS infants were known to be echographically patent; only blood samples collected after a clean venipuncture with immediate free-flowing blood were used for analysis in the reference group. Furthermore, all samples were immediately collected in soft plastic tubes containing appropriate anticoagulant to prevent activation of blood before processing of the samples.

Blood samples were taken on the first day of life within $12 \mathrm{~h}$ of birth, between 12 and $24 \mathrm{~h}$ of birth, and on the second, third, fourth, and fifth days of life. The first sample was taken before any medical treatment, including surfactant and administration of indomethacin or blood products, had occurred. Each blood sample was taken during routine blood sampling and used for measuring activation of clotting (platelet count, T-AT III, F XIIa), fibrinolysis (t-PA), and kinin-kallikrein (kallikrein activity; PKKI). At each sampling, $0.3 \mathrm{~mL}$ of blood was taken and anticoagulated with EDTA $(0.01 \mathrm{M})$ for determination of the platelet count; $0.5 \mathrm{~mL}$ of blood was anticoagulated with citrate $(0.3 \%)$ and centrifuged, and the plasma was stored at $-70^{\circ} \mathrm{C}$ until kallikrein activity, PKKI, F XIIa, and plasma concentration of t-PA were determined. Another $0.5 \mathrm{~mL}$ of blood was anticoagulated with hirudin-aprotinin and centrifuged, and the plasma was stored at $-70^{\circ} \mathrm{C}$. T-AT III complex was determined in this sample.

Assays. The platelet count was determined using a cell counter (Hemolog, Coulter Electronics, London, UK). F XIIa and kallikrein activity were determined according to a new method using a colorimetric assay (NovaBiochem, Laufelfingen, Switzerland) (15). Both F XIIa and kallikrein activity were expressed as \% AHP. PKKI was determined by a colorimetric assay (Kabi Diagnostica, Uppsala, Sweden) and expressed \% NHP. T-AT III complexes were determined using an enzyme immunoassay (Behring, Marburg, Germany). T-PA was determined by enzyme immunoassay (Kabi Diagnostica).

Statistical analysis. Data are presented as means \pm SD or as median with 25 th and 75 th percentiles as appropriate. Gestational age, birth weight, and arterial umbilical $\mathrm{pH}$ values in both groups were compared using the unpaired $t$ test; Apgar scores were compared using the Mann-Whitney $U$ test. The $\chi^{2}$ test with Yates' correction for continuity was used for comparison of nominal data.

For F XIIa and T-AT III complex, means of six observations were calculated for each individual infant and compared between the IRDS and reference groups using the Mann-Whitney $U$ test; thus, intergroup difference was tested for these parameters. Specific comparison of these values between groups was performed on $\mathrm{d} 1$ (within $12 \mathrm{~h}$ of birth) and $\mathrm{d} 5$ using the Mann-Whitney $U$ test. Within groups, the F XIIa and T-AT III complex values on $\mathrm{d} 2,3,4$, and 5 were compared with the values on $\mathrm{d} 1$ (within $12 \mathrm{~h}$ of birth) by means of the Wilcoxon signedrank test. For platelet counts, t-PA, kallikrein activity, and PKKI, statistical analysis was performed with twoway analysis of variance for repeated measures followed by paired or unpaired $t$ tests to determine differences between and within the IRDS and the reference group. Adjustment of the significance level for multiple comparisons was performed according to the Bonferroni correction as appropriate. $p$ values less than 0.05 were considered significant.

\section{RESULTS}

Ventilatory requirements of IRDS infants. Mean fraction of inspired oxygen and peak inspiratory pressure values were high at admission. Fraction of inspired oxygen values decreased significantly from $0.72 \pm 0.12$ within 12 h of birth to $0.40 \pm 0.20$ on the fifth postnatal day $(p<$ $0.01)$. Peak inspiratory pressure values decreased from $24 \pm 2 \mathrm{~cm} \mathrm{H}_{2} \mathrm{O}$ within $12 \mathrm{~h}$ of birth to $21 \pm 6 \mathrm{~cm} \mathrm{H}_{2} \mathrm{O}$ on d 5 (not significant).

$\boldsymbol{F} \boldsymbol{X I I a}$. The IRDS and reference groups differed significantly with respect to their mean F XIIa values $(p=$ 0.017 ). F XIIa was slightly but not significantly higher in the group of IRDS infants than in the group of reference infants on the first day of life [5\% (0-22\%) AHP versus 
$2 \%(0-7.5 \%)$ AHP; not significant], but it was significantly higher on the fifth day of life [37\% (4.5-121\%) versus $0 \%(0-1 \%)$ AHP; $p<0.05]$. F XIIa increased significantly from within $12 \mathrm{~h}$ of birth to the 5 th $\mathrm{d}$ of life in the IRDS group $(p<0.05)$ but did not change in the reference group [Fig. 1, data shown as median (25th-75th percentile)].

T-AT III complex. Mean T-AT III complex plasma concentrations of the IRDS and the reference group were significantly different $(p=0.030)$. On the first day of life, the T-AT III complex concentration of the IRDS infants was significantly higher than that of the reference infants [90 (23-720) ng/mL versus $10(7-22) \mathrm{ng} / \mathrm{mL} ; p<0.05$ ]. The difference disappeared within $3 \mathrm{~d}$ due to a significant decrease $(p<0.05)$ of the T-AT III complex concentration to 8 (3-14) $\mathrm{ng} / \mathrm{mL}$ on d 5 [Fig. 2, data shown as median (25th-75th percentiles)]. T-AT III complex plasma concentrations did not change significantly in the reference group.

Platelet count. The platelet count of the IRDS group was lower than that of the reference group from as early as 12-24 $\mathrm{h}$ after birth, with the difference being significant on $\mathrm{d} 5(p<0.01)$. The platelet count of the IRDS infants decreased significantly from $205.5 \pm 65.0 \times 10^{9} / \mathrm{L}$ within 12 h of birth to $129.5 \pm 97.9 \times 10^{9} / \mathrm{L}$ on d $5(p<0.05)$; the platelet count of the reference group increased from 219.3 $\pm 67.4 \times 10^{9} / \mathrm{L}$ within $12 \mathrm{~h}$ of birth to $291.7 \pm 100.8 \times$ $10^{6} / \mathrm{L}$ on $\mathrm{d} 5(p<0.05)$ (Fig. 3).

$t-P A$. During the first $5 \mathrm{~d}$ of life, the t-PA plasma concentration of the IRDS group was higher than that of the reference group. On both d 1 and $\mathrm{d} 5$, the difference

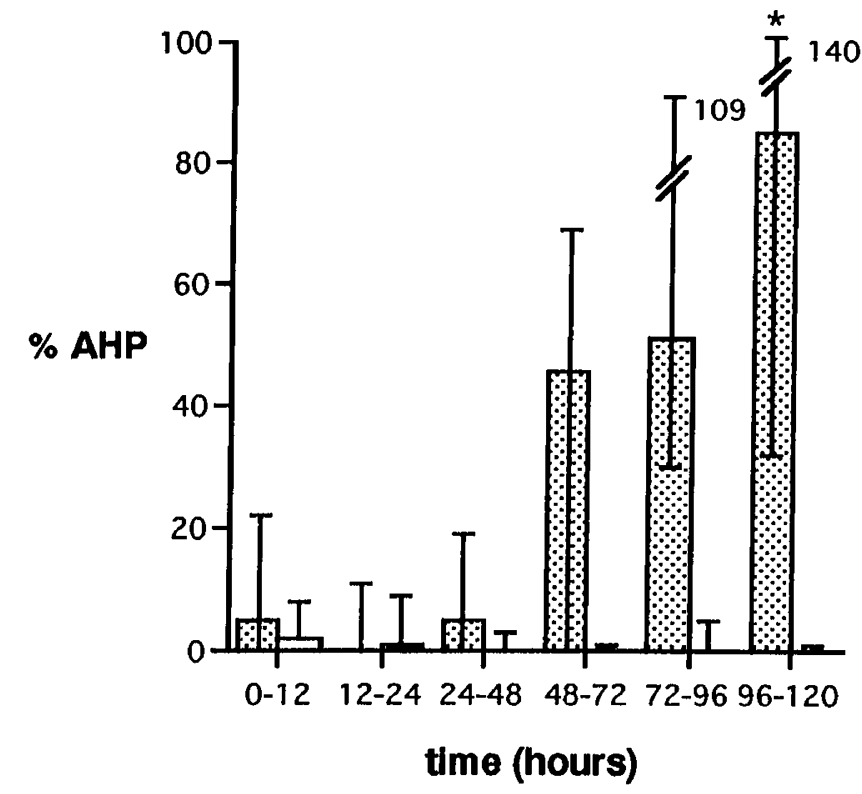

Figure 1. Plasma F XIIa in preterm infants with IRDS (stippled columns) and healthy preterm infants (open columns) during the first $5 \mathrm{~d}$ of life. F XIIa is expressed as \% AIP. The columns represent the median value; the error bars represent the $25 \mathrm{th}$ and 75 th percentiles of the values. The 75th pereentile error bars of the IRDS group an 72.96 and $96-120)$ h after birth are eompressed and the value indicated. ${ }^{*}, p<0.05$ compared with ()-12 h.

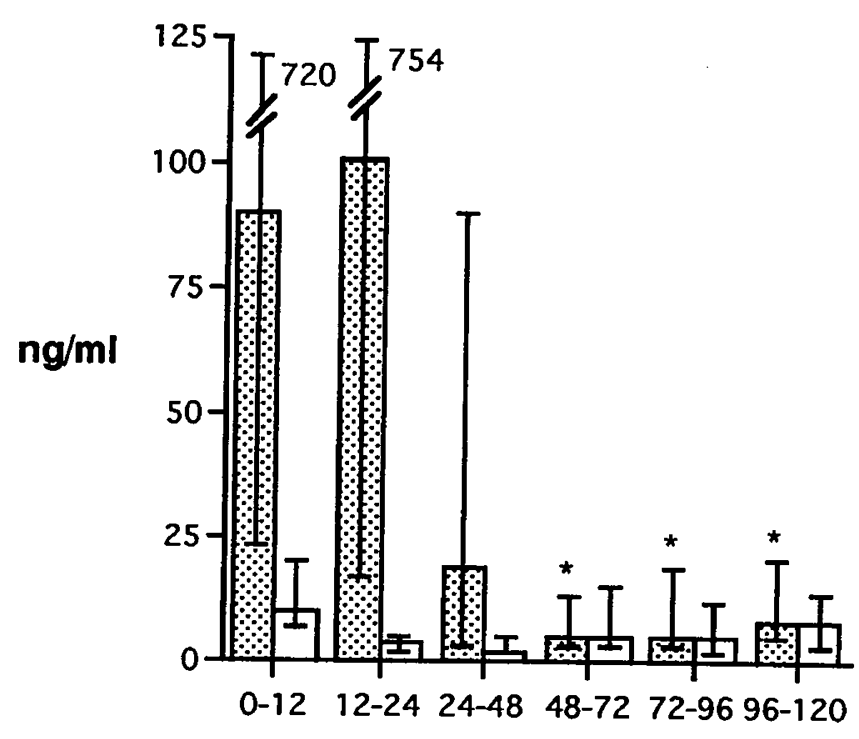

time (hours)

Figure 2. Plasma concentrations of T-AT III complex in preterm infants with IRDS (stippled columns) and healthy preterm infants (open columns) during the first $5 \mathrm{~d}$ of life. The columns represent the median value; the error bars represent the 25 th and 75 th percentiles of the values. The 75th percentile error bars of the IRDS group at 0-12 and $12-24 \mathrm{~h}$ after birth are compressed and the value indicated. ${ }^{*}, p<0.05$ compared with () $12 \mathrm{~h}$.

was significant $(p<0.05)$. The t-PA plasma concentration decreased significantly from $11.8 \pm 4.8 \mathrm{ng} / \mathrm{mL}$ within $12 \mathrm{~h}$ of birth to $5.0 \pm 2.5 \mathrm{ng} / \mathrm{mL}$ on $\mathrm{d} 5$ in the IRDS group $(p<0.05)$ and from $3.5 \pm 3.4 \mathrm{ng} / \mathrm{mL}$ to $1.3 \pm 1.2 \mathrm{ng} / \mathrm{mL}$ in the reference group (not significant) (Fig. 4).

Kallikrein activity. The plasma kallikrein activity increased in the IRDS group from $182.6 \pm 39.8 \%$ AHP within $12 \mathrm{~h}$ of birth to $207 \pm 18.3 \%$ AHP on d 5 (not significant) and decreased in the reference group from 162 $\pm 10.6 \%$ AHP to $159 \pm 7.0 \%$ AHP (not significant) (Fig.

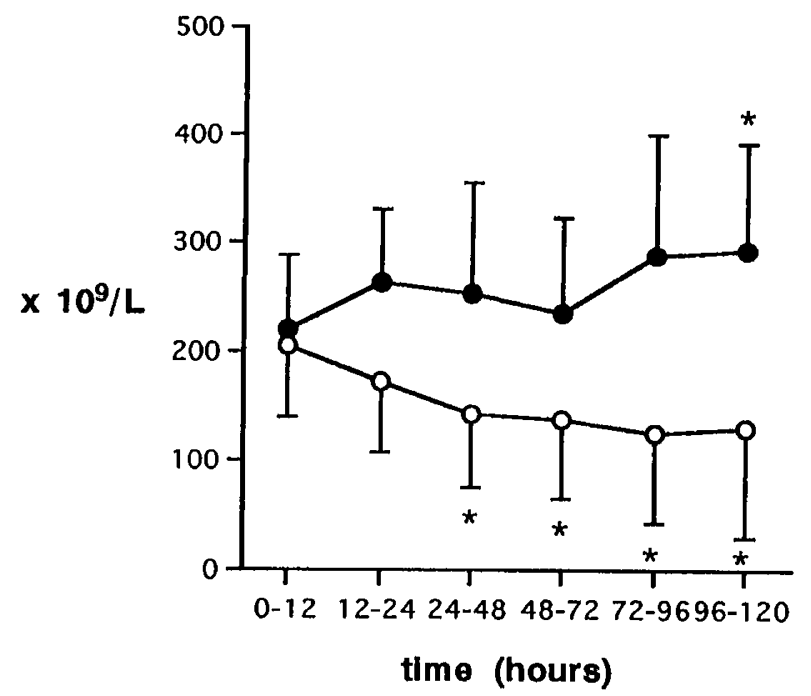

lïgure 3. Platelet count in preterm inlants with IRDS (open circles) and healthy preterm infints (filled circles) during the first 5 ol of life. Data are expressed as mean \pm SD. ${ }^{*}, p<0.05$ compared with ()-12 h. 


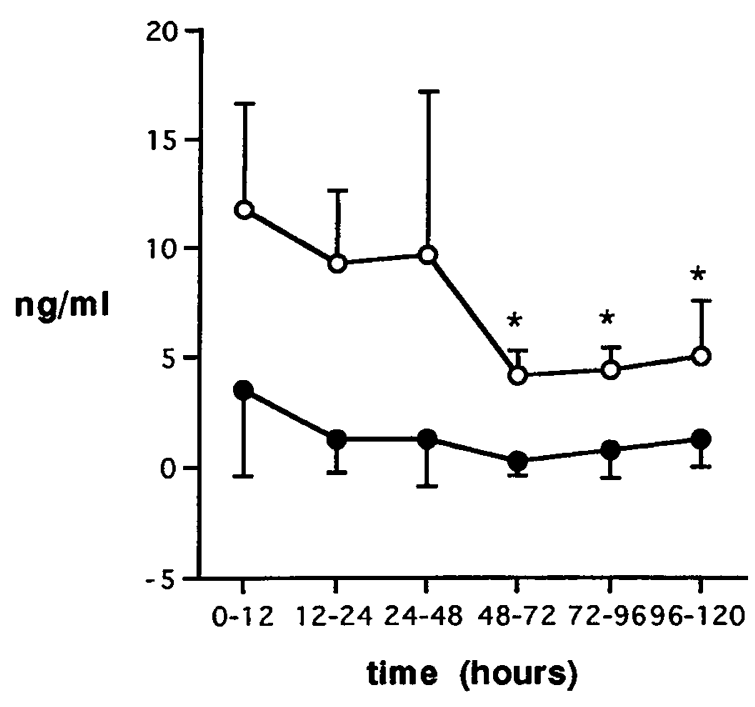

Figure 4. Plasma concentrations of t-PA in preterm infants with IRDS (open circles) and healthy preterm infants (filled circles) during the first $5 \mathrm{~d}$ of life. Data are expressed as mean $\pm \mathrm{SD} .{ }^{*}, p<0.05$ compared with $0-12 \mathrm{~h}$.

5). The two groups differed with respect to the plasma kallikrein activity during the first $5 \mathrm{~d}$ of life, with the difference being significant on $\mathrm{d} 5(p<0.01)$.

$P K K I$. PKKI values of the IRDS group were lower than those of the reference group throughout the study period; the difference was significant on $\mathrm{d} 1(p<0.05)$. PKKI values in the IRDS group increased significantly from 44 $\pm 10 \%$ NHP within $12 \mathrm{~h}$ of birth to $60 \pm 12 \%$ NHP on d $5(p<0.05)$. These values increased in the reference group from $61 \pm 7 \%$ NHP within $12 \mathrm{~h}$ of birth to $75 \pm 9 \%$ NHP on d 5 (not significant) (Fig. 6).

\section{DISCUSSION}

In this study, we have found simultaneous activation of the clotting, fibrinolytic, and kinin-kallikrein systems in a

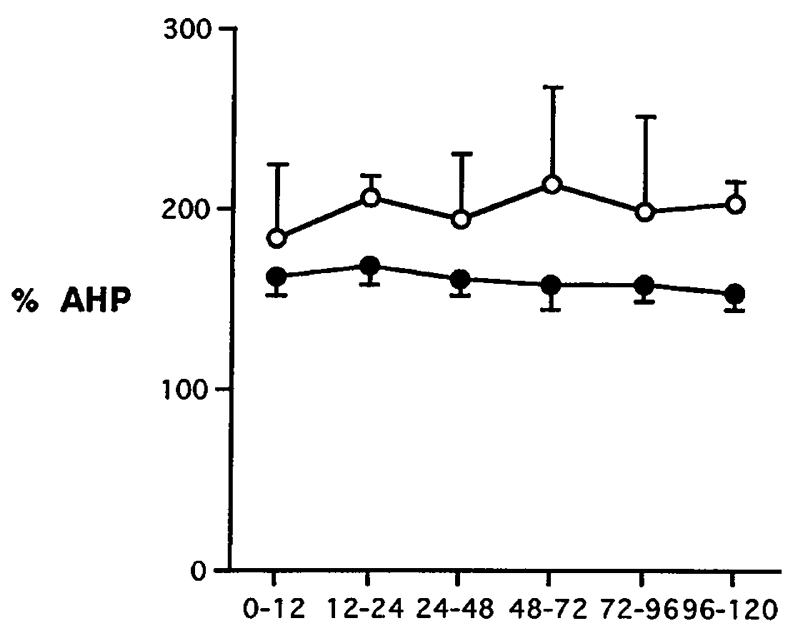

time (hours)

Figure 5. Plasma kallikrein activity in preterm infants with IRDS (open circles) and healthy preterm infants (filled circles) during the first $5 \mathrm{~d}$ of life. Kallikrein activity is expressed as \% AHP. Data are expressed as mean $\pm \mathrm{SD}$.

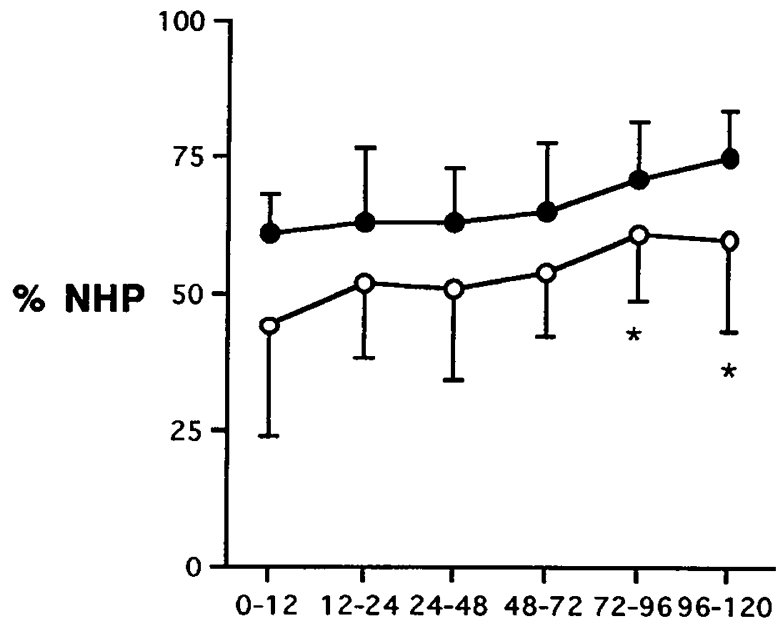

\section{time (hours)}

Figure 6. PKKI in preterm infants with IRDS (open circles) and healthy preterm infants (filled circles) during the first $5 \mathrm{~d}$ of life. PKKI expressed as \% NHP. Data are expressed as mean \pm SD.

group of 10 preterm infants requiring artificial ventilation from birth and with clinical and radiologic signs of IRDS (IRDS group). Clotting and fibrinolytic activity decreased in these infants within the first 2 to $3 \mathrm{~d}$ of life. F XIIa increased significantly in the IRDS infants from the third day of life. We observed kallikrein generation accompanied by decreased PKKI throughout the study period.

Activation of the clotting system in the IRDS group was represented by increased T-AT III complex plasma concentrations within $12 \mathrm{~h}$ of birth. T-AT III complex formation is a sensitive marker of thrombin generation (16), which is the key event in clotting. Schmidt et al. (4) have found increased T-AT III complex plasma concentrations accompanied by low AT III (the main inhibitor of thrombin) plasma concentrations in 3-d-old preterm infants with severe IRDS, which suggests AT III consumption due to intravascular clotting. Low AT III concentrations, in turn, limit the potential for neutralization of thrombin, the generation of which is maintained in sick preterm newborn infants (17). Insufficient neutralization leaves thrombin capable of activating platelets and converting fibrinogen to fibrin. After activation by thrombin, platelets aggregate, thus inducing a decrease in the platelet count. We have found a significant decrease of the platelet count in the IRDS infants, which is in accordance with findings of Kohelet et al. (18). They also reported an association between the severity of the IRDS and the reduction of the platelet count in the first postnatal days. Other authors have demonstrated intravascular formation of fibrin thrombi and deposition of fibrin in hyaline membranes at autopsy in the lungs of preterm infants dying of severe IRDS $(1,2)$.

We have observed activation of the fibrinolytic system in the group of IRDS infants, which supports the findings of Suzuki (19). Fibrinolytic activation was represented by significantly higher t-PA plasma concentrations than 
those in the group of reference infants. Thus, preterm infants are able to raise t-PA plasma concentrations, as has been demonstrated by Corrigan and Jeter (20) in "stressed" 1- to 29-d-old infants with congenital heart disease. In the presence of fibrin, t-PA converts plasminogen into plasmin. Plasmin causes lysis of fibrin(ogen) with formation of fibrin(ogen) degradation products. However, plasminogen levels in preterm infants with IRDS are low (21). Therefore, fibrinolysis is thought to be insufficient in IRDS infants, which allows intravascular fibrin formation and intraalveolar fibrin deposition in these infants $(1,2)$.

We have observed in both the IRDS and the reference group higher kallikrein activity and lower PKKI values than in plasma of adults. This may be related to low plasma concentrations of the main kallikrein antiprotease $\mathrm{C}_{1}$ esterase inhibitor (22). In plasma of the IRDS infants, however, we have found higher kallikrein activity and lower PKKI than in plasma of the reference infants, indicating activation of the kinin-kallikrein system in the IRDS group, which is in agreement with findings of Saugstad et al. $(23,24)$. Activation of the kinin-kallikrein system results in the formation of bradykinin $(25,26)$. Bradykinin has potent vasodilatory properties and increases capillary permeability $(10,26)$; it might therefore contribute to formation of pulmonary edema in IRDS infants, thus causing respiratory insufficiency.

The cause of the aforementioned activation of clotting, fibrinolysis, and kinin-kallikrein is not clear. Hypoxemia and acidosis are able to induce release of tissue factor and t-PA by activated endothelial cells, thus activating the extrinsic clotting pathway and the fibrinolytic system, respectively (27-29). As shown in our IRDS infants, high T-AT III complex and t-PA plasma concentrations at birth are associated with low Apgar scores and low arterial umbilical $\mathrm{pH}$ values at birth, indicating perinatal asphyxia (hypoxemia plus acidosis) $(30,31)$. Our data do not show an association between activation of clotting and fibrinolysis and ventilatory requirements of the IRDS group. T-AT III complex and t-PA plasma concentrations decreased significantly in our IRDS infants during the first 2 to $3 \mathrm{~d}$ of life despite ongoing artificial ventilation. On the contrary, formation of small amounts of activated factor XII can be induced by tissue trauma $(25,26,32)$. In preterm infants with IRDS, positive-pressure ventilation rapidly causes destruction of airway epithelium and increased permeability of vascular endothelium $(33,34)$. Hyperoxia also damages lung tissue (35). All IRDS infants required positive-pressure ventilation with increased oxygen concentrations in the inspired air throughout the study period. Simultaneously, plasma kallikrein activity was higher and plasma kallikrein inhibition lower in these infants than in the reference infants. Once activated factor XII has been formed, it strongly activates the kinin-kallikrein system and contributes to clotting and fibrinolytic activity $(36,37)$. Furthermore, kallikrein is the major plasma protein that, in turn, acti- vates factor XII $(26,36)$, which may explain the increase of F XIIa in our IRDS infants from the third day of life.

In this study, we have shown that during the first $5 \mathrm{~d}$ of life systemic activation of clotting, fibrinolysis, and kininkallikrein occurs simultaneously in preterm infants with clinical and radiologic signs of IRDS. This activation process seems to have a two-stage course. Whether this activation process is a consequence of hypoxemia and acidosis due to perinatal asphyxia or pulmonary tissue injury due to ongoing artificial ventilation is unknown. However, it may contribute to lung injury in preterm infants with IRDS by intravascular and intraalveolar fibrin deposition and pulmonary edema formation, as has been described in the adult respiratory distress syndrome (5-10). However, currently we do not know whether this process is associated with IRDS severity. Timedependent studies in preterm infants with mild, moderate, and severe IRDS on the activation of clotting, fibrinolysis, and kinin-kallikrein in plasma and its relation to the inflammatory process in the lung $(38,39)$ will further elucidate the role of this activation process in the pathogenesis of IRDS.

Acknowledgments. The authors thank J. Haan and F. Wei for their technical assistance and L. H. Kornman, M.D., for correction of the manuscript.

\section{REFERENCES}

1. Stark CR, Abramson D, Erkan V 1984 Intravascular coagulation and hyaline membrane disease of the newborn. Lancet 2:1180-1181

2. Peters M, Ten Cate JW, Breederveld C, De Leeuw R, Emeis J, Koppe J 1984 Low antithrombin III levels in neonates with idiopathic respiratory distress syndrome: poor prognosis. Pediatr Res 18:273-276

3. Jobe A, Ikegami M 1987 Surfactant for the treatment of respiratory distress syndrome. Am Rev Respir Dis 136:1256-1275

4. Schmidt B, Vegh P, Weitz J, Johnston M, Caco C, Roberts R 1992 Thrombin/ antithrombin III complex formation in the neonatal respiratory distress syndrome. Am Rev Respir Dis 145:767-770

5. Royall JA, Levin DL 1987 Adult respiratory distress syndrome in pediatric patients: I. Clinical aspects, pathophysiology, pathology, and mechanisms of lung injury. J Pediatr 112:169-180

6. Carvalho AC, Demarinis S, Scott CF, Silver LD, Schmaier AH, Colman RW 1980 Activation of the contact system of plasma proteolysis in the adult respiratory distress syndrome. J Lab Clin Med 112:270-277

7. Aasen AO, Smith-Erichsen N, Amundsen E 1986 Uncontrolled plasma proteolysis: a major threat to the septicemic patient. Resuscitation 14:33-42

8. Haynes JB, Hyers TM, Giclas PC, Franks JJ, Petty TL 1988 Elevated fibrin degradation products in ARDS. Am Rev Respir Dis 122:841-847

9. Malik AB, van der Zee $\mathrm{H} 1978$ Mechanism of pulmonary edema induced by microembolization in dogs. Circ Res 42:72-79

10. Aasen AO, Frolich W, Saugstad OD, Amundsen E 1978 Plasma kalikrein activity and prekallikrein levels during endotoxin shock in dogs. Eur Surg Res 10:50-62

11. Jansen NJG, van Oeveren W, van den Broek L, Oudemans-van Straten HM, Stoutenbeek CP, Chang Njoek Joen M, Roozendaal KJ, Eysman L, Wildevuur CRH 1991 Inhibition of the reperfusion phenomena in cardiopulmonary bypass by dexamethasone. J Thorac Cardiovasc Surg 102:515-525

12. Giedion A, Haefliger H, Dangel P 1973 Acute pulmonary x-ray changes in hyaline membrane disease treated with artificial ventilation and positive end expiratory pressure. Pediatr Radiol 1:145-152

13. Gu YJ, Obster R, de Haan J, Gallandat Huet RCG, van Oeveren W 1992 Biocompatibility of leukocyte removal filters during bedside leukocyte filtration of red cell concentrates. Transfus Sci 13:467-472

14. van Lingen RA, Hofhuis WDJ, Dekker I, Baerts W, Hählen K, Sauer PJJ 1992 The effect of heparin in arterial catheters on the coagulation in preterm infants. J Perinat Med 20:39-46

15. van der Kamp KWHJ, van Oeveren W 1994 Beta-factor XII a and kallikrein generation in plasma during incubation with biomaterials. J Biomed Mat Res 28:349-352

16. Pelzer H, Schwartz A, Heimburger N 1988 Determination of human thrombin-antithrombin III complex in plasma with an enzyme-linked immunosorbent assay. Thromb Haemost 59:101-106 
17. Shah JK, Mitchell LG, Paes B, Ofosu FA, Schmidt B, Andrew M 1992 Thrombin inhibition is impaired in plasma of sick neonates. Pediatr Res 31:391-395

18. Kohelet D, Perlman M, Hanna G, Ballin A 1990 Reduced platelet counts in neonatal respiratory distress syndrome. Biol Neonate 57:334-342

19. Suzuki S 1978 Blood coagulation and fibrinolysis of the newborn viewed as perinatal factors. II Fibrinolytic studies in the respiratory distress syndrome of the newborn infant. $J$ Perinat Med 6:46-58

20. Corrigan JJ, Jeter MA 1992 Tissue-type plasminogen activator, plasminogen activator inhibitor, and histidine-rich glycoproteins in stressed human newborns. Pediatrics 89:43-46

21. Markarian M, Githens JH, Rosenblüt E, Fernandez F, Lang D, Jackson JJ, Bannon AE, Lindley A, Githens JH, Martorell R 1971 Hypercoagulability in preterm infants with special reference to the respiratory distress syndrome and hemorrhage. I Coagulation studies. Biol Neonate 17:84-97

22. Andrew M, Massicotte-Nolan P, Karpaatkin M 1983 Plasma protease inhibitors in premature infants: influence of gestational age, postnatal age, and health status. Proc Exp Biol Med 173:495-500

23. Saugstad OD, Buo L, Johansen HT, Roise O, Aasen AO 1992 Activation of the plasma kallikrein-kinin system in respiratory distress syndrome. Pediatr Res 32:431-435

24. Saugstad OD, Harvie A, Langslet A 1982 Activation of the kallikrein-kinin system in premature infants with respiratory distress syndrome (RDS). Acta Paediatr Scand 71:965-968

25. Colman RW 1984 Surface-mediated defense reactions: the plasma contact system. J Clin Invest 73:1249-1253

26. Kaplan AP, Silverberg M 1987 The coagulation-kinin pathway of human plasma. Blood 70:1-15

27. Nemerson Y 1992 The tissue factor pathway of blood coagulation. Semin Hematol 29:170-176

28. Manco-Johnson M 1992 Pathophysiology of neonatal disseminated intra- vascular coagulation and thrombosis. In: Polin RA, Fox WW (eds) Fetal and Neonatal Physiology, Vol 2. WB Saunders, Philadelphia, pp 1394 1399

29. Collen D 1980 On the regulation and control of fibrinolysis. Thromb Haemost 43:77-89

30. American Academy of Pediatrics 1986 Use and abuse of the Apgar score. Pediatrics 78:1148-1149

31. Thorp JA, Sampson JE, Parisi VM, Creasy RK 1989 Routine umbilical cord blood gas determinations. Am J Obstet Gynecol 161:600-605

32. Clark RAF 1988 General considerations of wound repair. In: Clark RAF, Henson PM (eds) The Molecular and Ceil Biology of Wound Repair. Plenum Press, New York, pp 3-33

33. Nilsson R, Grossmann G, Robertson B 1978 Lung surfactant and the pathogenesis of neonatal bronchiolar lesions induced by artificial ventilation. Pediatr Res 12:249-255

34. Jobe A, Jacobs H, Ikegami M, Berry D 1985 Lung protein leaks in ventilated lambs: effect of gestational age. J Appl Physiol 58:1246-1251

35. Saugstad OD 1990 Oxygen toxicity in the neonatal period. Acta Paediatr Scand 79:881-892

36. Heimark RL, Kurachi K, Fujikawa K, Davie EW 1980 Surface activation of blood coagulation, fibrinolysis and kinin formation. Nature 286:456-460

37. Hathaway WE 1992 Normal hemostatic mechanisms. In: Polin RA, Fox WW (eds) Fetal and Neonatal Physiology, Vol 2. WB Saunders, Philadelphia, pp 1365-1368

38. Merritt TA, Cochrane CG, Holcomb K, Bohl B, Hallman M, Strayer D, Edwards DK 1982 Elastase and $\alpha_{1}$-proteinase inhibitor activity in tracheal aspirates during respiratory distress syndrome. Role of inflammation in the pathogenesis of bronchopulmonary dysplasia. J Clin Invest 72:656-666

39. Ogden BE, Murphy SA, Saunders GC, Pathak D, Johnson JD 1984 Neonatal lung neutrophils and elastase/proteinase inhibitor imbalance. Am Rev Respir Dis $130: 817-821$ 